Vol. 6(8), pp. 107-118, September, 2014

DOI: 10.5897/IJ PC 2014.0275

Artic le Number. F86A3A447577

ISSN 1996-0816

Copyright (c) 2014

Author(s) retain the copyright of this a rtic le

http:// www.academic joumals.org/IJ PC

\title{
International Journal of Psychology and
} Counselling

\section{Domestic violence, risky family environment and children: A bio-psychology perspective}

\author{
Olusegun Emmanuel Afolabi \\ Department of Educational Foundation, Faculty of Education, University of Botswana, Botswana.
}

Received 11 August, 2014: Accepted 18 September, 2014

\begin{abstract}
Though a large body of research has investigated the impacts of domestic violence on adult's victims, only few studies has been devoted to the exposure of children's to probable inter-spousal trauma that disrupts their neurological and biochemical pathways in development. The aim of this paper is to analyze the current empirical research that discusses the biological and psychological inference of domestic violence and risky family environment on children's health. In realizing this objective, the paper used the ecological framework to explain the interaction effects of bio- psychological processes on emotional regulation and social competence skills of children living in a domestic violence and risky family environment. Finally, study shows that a risky and harsh early family environment exacerbates disturbances in children' physiological and neuroendocrine responses to stress, and also has longterm adverse implication on their mental health.
\end{abstract}

Key words: Domestic violence, risky family environment, mental health.

\section{INTRODUCTION}

When we deliberate about the impacts of household violence and risky family environment on children's wellbeing, we are looking at the implication of a child living in a home where marital conflict and spousal violence is happening. Domestic violence is globally described by various scholars, academicians and professionals in human development and public health as a stern social problem, and to say the least, a human rights violation. The recent debate over the years on the issue explains the significant influence it has on mental health of young children. Besides, a broad research evidence also indicates how intensely is risky family environment for children's wellbeing (Cummings and Davies, 1994; Margolin and Gordis, 2000, Mathias et al.,
1995; Zeanah et al., 1999). Although the awareness about the ordeal of children induced by family violence are well mentioned in various literature [McIntosh, 2009], both current and past literatures still labelled marital conflict as the strongest predictor of behavioural problems in children (Marshall and Watt, 1999) and was connected with internalized and externalized behavioural conducts in adulthood. As a baffling topic for academia, practitioners, and policy-makers, living in a domestic violence household influenced children's bio- psychosocial development and have deleterious impacts on their socio-cognitive functioning (Hetherington and Kelly, 2002). While evidence shows that most child victims are resilient, the significant few still suffer long-term adverse

*Corresponding a uthor. E-mail: a fo13@yahoo.com .

Author agree that this article remain pemanently open access under the terms of the $\underline{\text { Creative Commons Attribution }}$

License 4.0 Intemational Lic ense 
psychological and biological consequences in life (Hetherington and Kelly, 2002).

The main problem identified in literatures is how to connect the vulnerable young children with the probable inter-spousal trauma that disrupts their neurological and biochemical pathways in development (Dodd, 2009; Kershaw et al., 2008; Barnish, 2004; McGee, 1997; Humphreys, 2006). As mostly mentioned, the most cited predictive factors that promote negative outcomes in children are risky family environment (Cummings and Davies, 2010; Hetherington and Kelly, 2002). In addition, a collection of cross-sectional and future studies revealed that children reared in circumstances, i.e. irritable and quarrelling environment developed mental health problems earlier in life, i.e., conception to adulthood (Repetti et al., 2002). Therefore, a "risky families" is a childhood household milieu that promotes constant violence, as well as crisis ridden in lieu of warmth and nurturing milieu (Taylor et al., 2004). Children's early exposure to such complex environmental factor provokes different form of negative behaviour in their life. This experience hastens the acquisition of biological and psychological impairment that comes with trauma (Repetti et al., 2002).

Interestingly, the emergent research establishes a possible lasting legacies and relationship between childhood riskier family milieus and bio-psychosocial impairments in adult's age; similarly, other scholars like Repetti et al. (2002) also established a number of childhood's biological and psychological problems that are linked with the occurrence of dangerous household environments such as nervousness, behaviour disorder, antisocial conduct, and poor cognitive abilities to mention a few. Apart from the childhood implications it has on child victims, negative family exposures promote psychopathology in early adulthood, and later relates to decreased trauma responses, less significant self-rated health, plus poor social relations (Taylor et al., 2004). Besides, research also maintains that domestic violence (DV) experiences increase depressive symptoms in adults (Sen et al., 2010), nervousness intensities (Edge et al., 2009), as well as disturbed emotional processing (Taylor et al., 2006). In addition, children's household milieu also acts as a mediator for children's health and quality of life and dangerous family circumstances promote poorer sleep due to daily distress (Hanson and Chen, 2010). However, what is yet to be confirmed by most researchers on the topic is the interplay between biological and psychological processes that promote these negative outcomes.

\section{Purpose}

Differing to the enormous study on domestic violence, studies that address biological and psychological influence of living in a risky family environment are still new. Till date, research has not clearly solved the genetic basis for risky family environments and the impacts it has on a child's wellbeing. This paper analyses broad assessment of bio-psychological inference of domestic violence on children's mental health, and also examines the implications that such experience has on their emotional regulation and social skills. Besides, the paper also discusses broad research about childhood ordeal, particularly, in the context of domestic violence (Center for Disease Control [CDC], 2013; Chapman et al., 2013). Though, current research on bio-psychological processes of children living in a domestic violence environment emphasizes more on narrow topics, that is adult's victims, only a few offer a reliable framework for child victims of the incidence. Finally, an ecological framework that explains the interaction effects of biological and psychological processes of children witnessing domestic violence is presented in this study and possible areas for impending research are debated.

\section{METHODOLOGY}

This paper analysed and reviewed empirical literature in order to investigate and checked new empirical studies that link risky family environment and children' bio-psychological development. The study collated and reviewed relevant articles, books, journals, and meta-analysis of domestic violence, risky family environment and children's mental health. Both the ERIC and PSYCHLIT databases were searched using the following key words: domestic violence, risky family environment, children mental health, and biopsychological process. This procedure initially reported about 2283 articles, journals, technical reports, paper presentation and book chapters covering more than 20 year period. Based on the abstracts retrieved from this initial 2283 plus articles and publications, the search was lessened to a relatively few hundred of studies that are pertinent and relevant to the theme of this paper. The contents of the remaining several hundred of articles cum journals were further scrutinised and only those that reported empirical findings were kept aside and used in this review, while others were left out for further consideration. This process shows that only a few studies documented empirical findings about the link between living in a domestic violence or risky family environment and children bio-psychological processes. Even among those studies that document empirical analysis, only those that show Pearson correlations between risky family environment indicators and children biologically and psychological development were used. To verify references, manual searches of relevant journals and articles related to the paper are performed.

\section{Background information}

Overviews of domestic violence and children's mental health

Research continues to prove that young children are 
potential victims of domestic violence at home and these happens in different ways. A significant body of research argued that children living in a risky family environment are prone to health problems such as emotional and behavioural difficulties. For instance, a study conducted by Felitti et al. (1998) reported a robust association between early exposure to domestic violence and biopsychological disorders in adulthood. Also, scholars such Russek and Schwartz (1997) and Walker et al. (1999) reported a similar relationship between risky family environment and children's mental health. This among other research confirmed the link between children's health problem and their contextual environment (Repetti et al., 2002). The significant question that continues to generate debate in most literature is why early childhood experience of an adverse household is linked with such broad range of health problems that continue till adulthood.

Domestic violence remains an endemic and dangerous situation that impacts negatively on young people's health and has long-standing implications on their development (Peedicayil et al., 2004). In fact, most research identifies family, social and biological environment like, family's socioeconomic resources and inherited factors, as a contributing factor to a risky family social environment. For example, children's brutal exposure to household violence is often followed by many negative evolving factors such as, poverty, poor socio-cognitive functioning, mental health issues, femaleheaded household (Fantuzzo et al., 1997). Also, children living in such a risky household mostly get involved in violence. Most of these children feel that they can call for help, seek for support or branded as the main cause of the abusive situation. Although children live in ferocious households, they are prone to menace of physical harm both during prenatal and postnatal (Christian et al., 1997; Peedicayil et al., 2004). Besides, hereditary factors are also mentioned as a determinant of risky families. For instance, some characteristic that promotes and sustain risky family settings may have a genetic predisposition (Plomin et al., 2003). Therefore, children who are hereditarily inclined to particular difficulties (hyperactive or excessively inhibited temperaments) are adversely influenced by a risky household situation than those who are not exposed to such predating weaknesses. Till date, research has not clearly solved the genetic foundations for risky family environments and their impacts on children. This drawn global attention, particularly on the causes, effects and how it portends the biological and emotional wellbeing of young victims.

Though debate on DV is now globally embraced by various researchers, the focal point of most research on the topic was on the adult victims. The problem of abused women has been mounting over two decades, not until recently that the debate about their children receives much consideration and respect it deserved in research literature. While research demonstrates that young children respond to domestic violence in many ways, it is also confirmed that children who constantly experiencing occurrence of domestic violence against a parent bear the worst result of its effects later in life. The emotional disturbance displayed by such children is mostly noted by teachers in school, particularly, in their observation of traumatic violence exhibited when they play with peers, and by paediatricians in the hospital, when they assess children loss or slow developmental progress. Although some of these children are highly aggressive in their general dealing or relationship with peers, they also show signs of depression and withdrawal in their day-to-day activities (Osofsky, 1997).

Besides, most child victims of DV show signs of distress in their development. While some displays high sense of resilient to such negative exposure, others are adversely affected by the experience. Thus, this risk factor has adverse effects on individual children's biopsychological development. However, research documents a significant correlation amongst children witnessing DV and those physically maltreated (Kitzmann et al., 2003). They also established that children exhibited high levels of resilience to the harmful consequences of witnessing violence at home. Similarly, children living in violence household display sign of social and emotional problems, compared to those who never experience DV (Graham-Bermann, 2001). For instance, the higher the level of family or social support available to a child at risk, the more resistant he/she will be (Masten and Reed, 2002). On the contrary, positive parenting such as dynamic parenting, emotional and stable parents alleviate harm and danger in young children (Edleson et al., 2003; Levendosky et al., 2000; Sullivan et al., 2000) and confirmed the significance of early intervention on children's well-being (Jenkins and Bell, 1997). Despite this assertion, children raised in a domestic violence environment display a high risk of maladjustment in life compared to those from a violence free environment.

\section{Bio -ecological perspectives}

According to Swart and Pettipher (2005) and Lewis (2009) analysing individual proximal and distal environment is a basis for understanding the complexity in the individual's life, particularly the interaction and interrelationships between individual and the multiple systems that constitute his environment. As children grow up, they pass through different developmental stages that are influenced by the environment (Dawes and Donald, 2000). This constant interaction significantly influenced their behaviour either positively or negatively, depending on the circumstances they find themselves. Thus, trauma 
or misery does not only limit an individual in a system, but also occurs within diverse systems that form individual part. In lieu of this aforementioned, developmentalecological perspectives offer a useful framework for a better understanding of childhood exposure to risky environment. This theory highlights the significant impact that developmental processes, situational context, and numerous events and interaction has on adaptive as well as maladaptive growth (Rutter and Sroufe, 2000). The theory also linked household intricacy, social, and ethnic factors to developmental adjustments and abnormality in young children and made single-variable reasons held for more examination.

The bio- ecological framework explains how youngsters adjust to cruel situations in their environment, i.e., direct and indirect kinds of violence that compromise their adjusting methods and on-going development. Children's continuous exposure to DV impacts negatively on their biological and emotional adjustment and later leads to nervous and self-doubting approach in relationships which time and again manifest by robust feelings (e.g., frustration, dissatisfaction, aggression, panic). Also, children react differently to their exposure to DV by demonstrating different emotional problems. This is logical as it signifies child's adjustment to maladaptive circumstance. Though bio-ecological framework permits interaction and understanding at different levels within social systems, what is mostly unnoticed in the research literature about children's mental health is the significance of ecological factors that act as a mediator to violence.

Moreover, children experience violence in their home in three different ways, i.e. child abuse at the ontogenetic level, DV at household/micro system level and societal violence at the exosystem level. Nevertheless, research documents a significant correlation between those experiencing one of these types of violence and other forms of violence. McCloskey et al. (1995) submit that a man who subjects or physically abuses his wife is more probable to physically harm his offspring. Research also argues that there is a relationship between children's experience of chronic societal violence and intra-family skirmish (Osofosky et al., 1993, Richters and Martinez, 1993). Also, developmental risk literatures demonstrate that children who experience maltreatment at home are also victims of community anguish and that multiple risk factors upsurge youngsters 'menace for maladjustment exponentially.

In addition, Rutter (1997) established that children who experience abuse and ill-treatment at home are at risk of developmental psychopathology. This assertion supports the general beliefs that ecological influences (compensatory factors) guard youngster from negative life exposure and reduce danger of poor developmental effects. Unfortunately, only few researches focus on these brother ecological issues due to lack of child'scentred multi-disciplinary frameworks that embrace developmental preclusion and treatment exertions for offspring experiencing DV. On the other hand, research on marital conflict has come up with a heuristic hybrid process to increase our knowledge on how household and society menace directly or indirectly contribute to childhood psychopathology (Chiccetti, 1996, Rutter, 1997). Bio- ecological model advances future postulation about the consequence of household violence on youngsters' wellbeing by using rudiment research techniques and systematic philosophies of ecological theory and developmental psychopathology to analyse the relationship between domestic violence and child's development. This means that, ecology is contextually based and developmental psychopathology is child focused. Therefore, bio-ecological theory incorporates all the finest of these methods and covering the following mutually dependent foci of study: (a) understand the difficulty analysed in the context, (b) appreciate the influence of difficulty understudy on the youngster with an appreciation for the multidimensional of child's engagement, and (c) consider the significance of difficulty on child's activity over time. So, the process of examining children's outcome as a determinant of their development and transformation over time is a symbol of developmentally sensitivity investigation.

The model (Figure 1) demonstrates the constant interactions between an individual and the various systems that constitute his or her environments. This interaction has a, significant consequence on a developing child (i.e., biological and psychological) including the proximal environment that the child lives. However, the life experience that a child has, whether negative or positive, affects his wellbeing and development (Lewis, 2009). The question is how a child social context that consists of risky and violent conditions influences his development?

\section{The link between domestic violence and trauma}

According to Biersteker and Robinson (2000), family circumstance such as risky household environment influenced parenting style and parents' ability to support and care for their kids. Family interactions are threatened by ways parents relate or engage with each other. A child exposed to DV and risky family environment can display traumatic experiences. (DSM-IV-TR, 2000; Hamber and Lewis, 1997) and these traumatic situations affect their biological and psychological development. Children can develop continuous fear and panic for their safety with a feeling that this experience can harm them. Based on bio-ecological framework, whatever happen in a child's household environment has a significant effect 


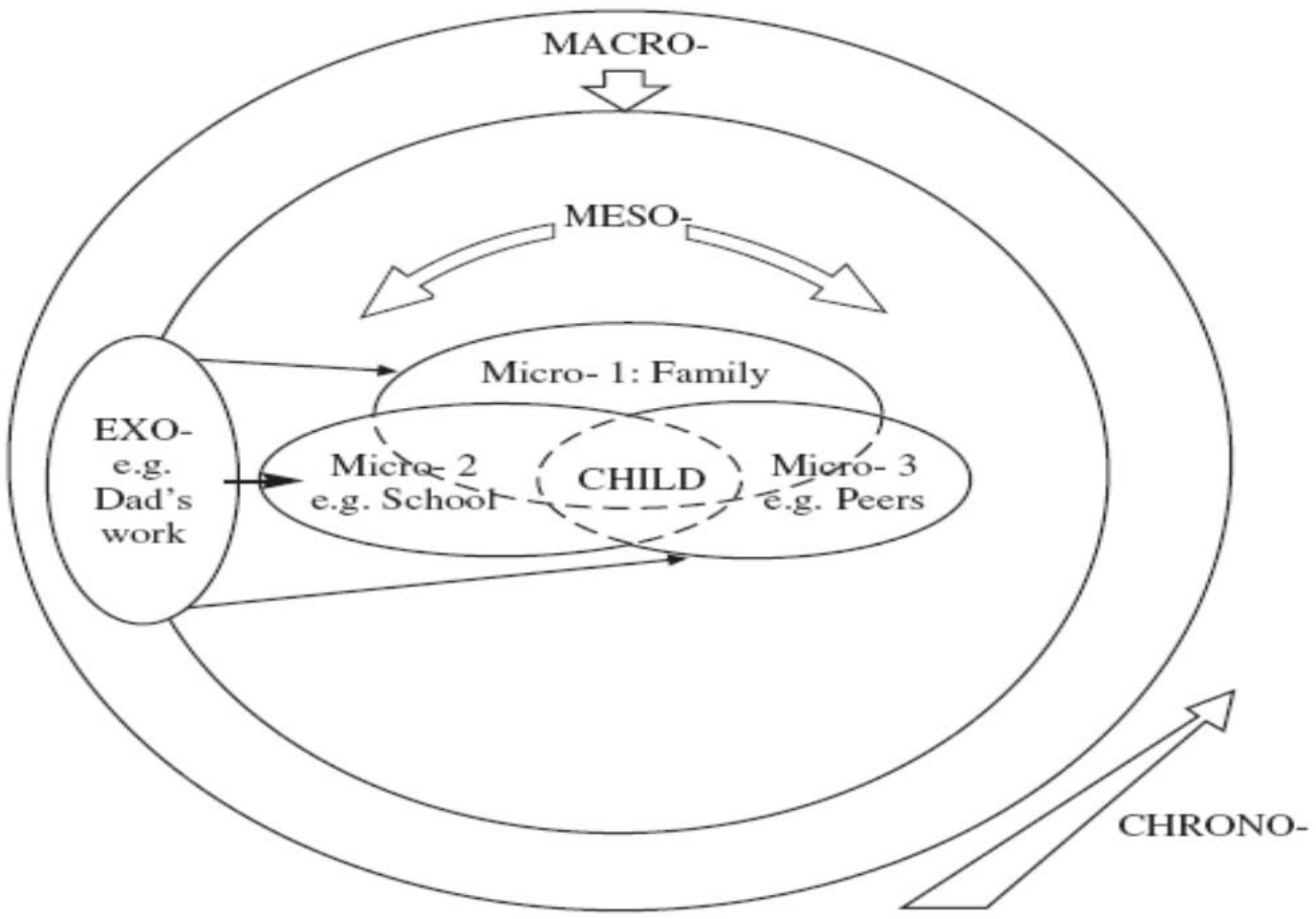

Figure 1. Bio-ecological model, from Donald et, al. (2006).

on his wellbeing and development (Bronfenbrenner, 1994), including his interaction with the environment. Scholars such as Gabowitz et al. (2008); Lewis, (2009) and Stavrou, (1993) maintain that children living in a DV environment displayed different behaviour such as fear (future attack or experience of violence), emotional changes (powerlessness, emotional numbing, and a lack of security). Children's emotional changes can also contribute to symptoms such as nervousness, restlessness, irritation and guiltiness. Similarly, children exposed to household violence experience lethargic, lack of energy, mood swing, sleeplessness and nightmare, poor social conduct and last but not the least, poor cognitive ability that affects their memory.

\section{Variability in children's adjustment to domestic violence}

Decades of domestic violence confirmed that the childhood risky family environment is major predictor of childhood disorder; yet, there are still significant individual differences. As mentioned earlier, children living in risky households are also victims of maltreatment and abuse (Hamby etal., 2010). The degree of exposure was reported as predicting adverse mental health signs
(Finkelhor et al., 2007). However, children's adjustment to risky family environment is influenced by individual differences in resiliency. Numerous protective factors such as easy personality; social skills; intelligence; positive parenting; and social network that relate to risk factors such as high temperament, low intelligence, poor social skills, parental depression and negative peer interactions are identified as defining vulnerability in youngsters (Hetherington and Kelly, 2002). Therefore, household milieu and child's physiognomies are vital in explaining the impacts of childhood risky family environment on children' mental health.

Besides, diathesis stress model explains psychosocial stressor by analyzing individual's past knowledge, including the bio-psychological and social vulnerabilities (Sbarra et al., 2012). These pre-disposing features are related to both the distal and proximal effects surrounding the stressor, i.e. witnessing domestic violence. The life stressors for young children vary due to the level of stress they can condone, and it reflects their individual susceptibilities. Children experience DV through different susceptibilities, founded on bio- psychological tendencies and life experiences. However, the interface between experiences related to stressor, biological inclinations, and life histories impacts on post stressor modification stage. Though most youngsters show sign of resilience 
and exhibit normal functioning following their exposure to household violence, nonetheless, the majority of children victims demonstrate important signs of instability in life. These types of children represent those that are brought up in a high risky family environment where annoyance and violence is highly related with parental psychopathology (depression), drug abuse, and negative child-rearing (Cummings and Davies, 2010; Repetti et al., 2002). Such youngsters are prone to fixation and stressrelated issues that cut across several areas.

\section{Parenting Capacities}

Research shows that children's exposure to DV is not only influenced by the situation of abuse, but also by the relationship they experience with their parent/families, i.e. be it the culprit or the target of the violence. This invariably influences the value of the parent - child relationship. Mullender et al. (2002) submit that parents perceive domestic violence as having a negative influence on their parenting. Also, Holtzworth-Munroe et al. (1997) conclude that nearly one or two third of those women experiencing domestic violence exhibit high significant experiences of low self-esteem, post-traumatic stress disorder and despair. Besides, reports, documents that mother may experience a regularly overwhelmed state of mind and still show signs of withdrawal or be emotionally unstable to meet her child's need. However, the most significant roles of any parents are to bring life into the child's world; making their experience manageable and bearable; and support children to develop their cognitive ability. Parents should make emotional sense of what has happened to them; give thought and reflection; and last but not the least, permitting the child to assimilate information (Mclntosh, 2002).

Likewise, child's development is highly affected or compromised when parents are separated from emotional experiences of DV. Williams (2003) affirms that the contexts of family violence influence the health and well-being of the caregiver and threaten practicability of the father-child interaction. Mostly, DV impacts negatively on parenting skills and prompts most abused parents to start worrying about their own needs (Sullivan et al., 2004). Similarly, domestic violence is linked to maternal control and discipline (Holt et al., 2008). Rivett and Kelly (2006) establish that women are liable to the emotional and wellbeing of their children and they are blamed for any kinds of emotional disturbance in their development. Similarly, Humphreys (2006) reports that the maternal authority is highly undermining where a child witnesses the mother being abused, as this will continue to torment the child even after the family has moved out of the abusive home. Buckley et al. (2007) state that most adolescents display sign of challenging behaviours after exposing to violence in their dwelling home; for instance, children show bad conduct such as physical aggression against their mothers; school refusal and stealing even after leaving the abusive home. However, the general consensus on the subject confirms the significant importance of parenting capacity by maintaining that mother's parenting skills cannot be under-estimated in child's development.

\section{Moderating factors}

Despite conceptual inconsistencies observed in earlier literature on domestic violence, research has reliably confirmed that characteristics such as positive and supportive caregiver; warmth parenting; parenting stability; child engaging temperament are significantly associated with resilience (Masten et al., 1999; Tate et al., 1998; Wyman et al., 1999). Similarly, reports document a highly significant correlation between positive adaptation and lower level of risk, such as less parental psychopathology; life anxiety; poverty; and membership of most cultural group (Bradley and Corwyn, 2002; Leech et al., 2006) and negative implications that come with children living in a DV environment (Kitzmann et al., 2003). Also, limited research explains various characteristics that describe children who keep up a positive adaptation despite their exposure to domestic violence (Grych et al., 2000; Hughes and Luke, 1998). This demonstrates that childhood exposure to DV is based on the interaction of an array of risk and resilience factors. On the other hand, Sternberg et al. (2006) reiterate that child's age does not moderate on internalizing behaviour, although older children were at a greater clinical risk. Besides, early exposure to DV impacts negatively on child's development comparable to the old age due to the negative influences on the subsequent chain of development (Holt et al., 2008).

\section{Domestic violence and developmental stage}

Recent research on domestic violence highlights biological processes that explain negative outcomes in children. Studies confirmed a significant relationship between exposures to hostile life experiences such as IPA and children's socio-cognitive functioning. It is reported that children living in a DV or high risk environment at the age of three are likely to impact negatively on their memory and cognitive functioning by the age of five (Gustafsson et al., 2013). Also, Gewirtz and Edleson (2007) established that the most identified primary developmental tasks of infancy are forming affection with the main caregiver. Yet, to achieve 
complete dependency, an infant needs a primary caregiver that is passionately sensitive to his needs, promotes a sense of confidence and security and offer safe or enriching environment for him to explore. Similarly insecure attachments are built up when parents fail to respond adequately to their baby's needs. Gerhardt (2004) explains that DV disturbs children's attachment relationships in a family. The emotional regulation problems between parents and children form the root of their insecure attachment and cause anxiety for young children. Moreover, failure to address this problem contributes to negative child's physiological responses such as neuronal networks and biochemical functioning. This distorts the stress response and generates high levels of cortisol in the brain region.

Also, research confirms that distress influences children's stress response system up till the age of three. Likewise, early exposure to stress influences a child's ability to respond positively to future stress (Gerhardt, 2004). Nevertheless, with the coexisting psychological expectations, this experience creates an emotional framework that guides individual's responses. Similarly, Cummings et al., (2009) affirm that children respond to family violence through integration of both biological and psychological processes. On the other hand, biopsychosocial model of emotional and physiological reactivity is a strategy that supports children witnessing domestic violence and that children's regulatory process is a moderating factor in their adjustment to violent situations.

Additionally, contemporary studies show that toddlers and pre-school children face increasing developmental challenges in life. Besides, Gewirtz and Edleson (2007) highlight the significant importance of child' learning to their behaviour. They conclude that emotional and cognitive states become important as a child learns to comprehend and manage his emotions through interaction with sensitive and responsive primary caregivers. Similarly, Cicchetti and Toth (2005) maintain that maltreatment is a risk for development of effective regulation in young children and limits their recognition, understanding and expression of emotion. As a consequence of their developmental limitations, young children seek alternative ways to express themselves. Thus, McGee (1997) maintains that children exposed to domestic violence (CEDV) manifest or show their distress in different forms.

Some of these children react with aggression, destructive and externalizing behaviours, while others show no sign or form of behavioural changes in life. On the other hand, some children react emotionally to fearful inhibited or over controlled and internalizing behaviours. Moreover, Carlson (2000) establishes that because of anxiousness and concern for their safety children react clingy and needing. Research also explains that fear is significantly related to psychosomatic problems; e.g., headaches; stomach aches (Holt et al., 2008). Also, Osofsky (2003) establishes that children are vulnerable to domestic violence situation and they display signs of distress through regression in language and toileting. Therefore, children of school age need to negotiate an increasingly complex social milieu and develop necessary skills that will help them to improve and develop effective communication with their peers and people around them. Furthermore, research shows that children react and understand their exposure to domestic violence either through externalizing or internalizing behavior and this variably or invariably impacts on their social competence in such contexts.

Besides, Gewirtz and Edleson (2007) highlight that some children exhibit lesser social competence and this influences the way they observe or misinterpret social cues in their environment. Likewise, research indicates that some children display common attitudes and think that the best way to manage conflicts or aggression is through violence (Osofsky 2003). Moreover, this attitude and behaviour if not properly addressed can lead to conduct disorder and disobedience in a school setting (Carlson 2000). Also, Cicchettin and Toth (2005) confirm that maltreated children show more of antisocial behaviors and less pro-social ones compared to those from enriching and friendly environment. Carlson (2000) maintains that children who experience DV display poor peer relationship, low self-esteem, anxiety and depression. This emotional reaction includes severe anxiety and post-traumatic stress disorder (PTSD), hyper alertness, emotional numbing and flashbacks (Carlson 2000).

\section{Biological Processes}

Repetti et al. (2002) linked early children's exposure to risky and chaotic family environment to discrepancies in emotion-regulation skills and negative emotional development in life. The fact that children living in violent household display chronic negative emotional development earlier in life makes negative experience a probable indicator of disturbances in emotion-regulation skills and contenders for facilitating the link between early family environment and child's mental health. For instance, aggression has been linked to coronary heart disease (Dembroski et al., 1985); epidemiological indication explains dose-response association of nervousness to coronary heart infection (Kubanski et al., 1998). Likewise, major despair, low-spirited symptoms, history of dejection, and nervousness are recognized as predicting cardiac actions (Frasure-Smith et al., 1995); Children's proximal and distal environment is also reported as vital in determining heirontogenetic 
development. For instance, an enriching rearing environments characterized by positive household relationships that promote care, responsiveness and engagement is tied to a constructive developmental outcome in children. However, punitive, split and unpredictable family settings is linked with maladjustment (Cicchetti and Howes, 1991; Cummings and Davies, 1994; Dunn and Davies, 2001; Sturge-Apple et al., 2006). Earlier research on development and family study explained the fundamental mechanisms that explain such associations. Most studies define the descriptive component of children's emotionality (Cummings et al., 2006), mental functioning (Grych et al., 2003; Jouriles et al., 2008; Sturge-Apple et al., 2008), and behavioural functioning (Gordis et al., 2001) of bio-ecological model.

Still, quite a little acknowledged children's biological functioning in the context of numerous family interactions. This is mostly important looking at the dominant role attributed to children's biological functioning in a household environments dominant of family menace (Boyce and Ellis, 2005; Repetti et al., 2002). Conversely, to identify the links of abnormalities in youngsters' biological functioning, it is imperative to explore whether risky family environment coupled with poor parental care predict child's adrenocorticol reactivity to consistent, laboratory processes planned that provoke youngsters' anguish in interparental and child-parent interaction. Neurobiological frameworks explained the importance of comprehending the function of hypothalamic-pituitaryadrenal (HPA) axis stress response system in a domestic situation (Cicchetti, 2002; Repetti et al., 2007; Susman, 2006). This works as a means of organizing resources that tackle ecological risk and distress.

The results of HPA stimulation are glutocorticoid hormone cortisol. Therefore, an increase in cortisol stages which come as a result of ecological stressor aid the adaptive role of increasing cognitive handling of meaningfully important actions, and rallying vigour and biological means to tackling stressor (Gold and Chrousos, 2002; Gunnar and Quevedo, 2007). Also, interparental violence and unresponsive punitive parental behaviours are considered as noticeable ecological pathogens on children's behaviour because of their pernicious on their security and welfare (Cicchetti and Rogosch, 2001; Margolin, 2005). Based on the stresssensitive characteristic of the HPA axis, interparental violence coupled with parent's emotional unobtainability is a strong prognosticator of uniqueness in youngsters' adrenocortical functioning.

\section{Stress response system}

The stress response system contains the Sympathetic Nervous System (SNS) and the Hypothalamic-Pituitary
Adrenocortical (HPA). However, the tendency to concurrently establish a links between interparental, child-rearing risk factors and youngsters' cortisol functioning permits influential tests for two conflicting models of stress response. According to the work of Davies and Cummings (1994) and Davies and SturgeApple (2007), emotional security theory provides important way to define the comparative practicability of broad stress and stress-specificity theory in a household. Emotional security is seen in an interparental and childparent's interactions as the most important objective for offspring. Children with long histories of interparental problems develop poor emotional safety in such environment. Research suggests that experience spells of violence, hostility, and skirmish in a household is a strong threat to children's wellbeing and increases fears about their security and safety in the family. On the other hand, EST suggests that maternal difficulties that promote poor attention, sensitive, and approachable parenting weaken children's confidence if they face any problem outside their home and no caring and reliable parents to help them (Cicchetti et al., 1998; Levondosky and Graham-Bermann, 2000). Given its importance to family measures, emotional security theory offers theoretical outline that explains the unambiguousness between children with histories of interparental and childparent rapport and biological reactivity paradigms that explain children's worries and safety in a household

\section{The interaction of biological and psychological responses}

Research has linked the higher menace of both internalizing and externalizing difficulties in youngsters to dysregulation in the stress response system that comes with trauma-related experiences (Luecken and Lemery, 2004; El-Sheikh et al., 2009). Reports also show a significant correlation between augmented stimulations of the HPA axis, internalizing conducts, and undesirable long-standing physical health effects (El-Sheikh et al., 2001). Similarly, the HPA axis is a probable trajectory for the solution of high conflict on youngsters' coping reactions, and it clarifies some distinctness observed in their behaviour. According to Koss et al. (2013), kindergarten- aged children demonstrate three patterns of cortisol fluctuation. For instance, a participant group displayed no variation between baseline, conflict, and resolve (11 percent), while another group exhibited a stable decline from baseline to resolve that in line with the diurnal rhythm of cortisol (77 percent), and last but not the least, the last group displayed a stable upsurge in cortisol levels (11 percent). More often than not, this report confirms that there is no relationship between the cortisol levels and emotional security, or adjustment, 
which means that kids react to domestic violence or high risk environment in different manners. Children who display increasing cortisol during baseline, conflict, and resolve are more probable to poor managing processes, higher levels of observed risk, emotional, and behavioural dysregulation. Besides, they are more probable to engage or interfere in violence (Koss et al., 2013).

\section{CONCLUSION AND RECOMMENDATION}

The impact of domestic violence on children' mental health is enormous. Studies continue to show that children who experience domestic violence or risky family environment develop social, emotional, and academic problems (Cummings and Davies, 2010). Although reports show numerous factors that influence child's adjustment, a well-established and reported experience documented is living in a domestic violence household. This prompts recent research on the likely effects of biological and psychological mechanisms that come as a result of children witnessing parental conflict. Though most studies illuminate the effect of children's exposure to risky family environment on cognitive development, surprisingly, it is established that children witnessing domestic violence before the age of three are more likely to develop memory impairment and poor cognitive functioning when they attain the age of five (Gustafsson et al., 2013).

Also, years of empirical evidence also proves that children from domestic violence household environment develop both biological and psychological health problems in their teenage years and in early adulthood. What most of these studies failed to emphasize is the probable interaction between biological and psychological developments in young children. Yet, research continually argued that living in a risky family household, such as domestic violence impacts negatively on the child's stress response system, as well as the SNS and HPA axis;a dysregulated stress response system that affects their sleeping ability and upsets others. Lastly, research demonstrates that child' emotional security is a pathway through which psychological process has biological outcomes (Cummings and Davies, 2010). Thus, if a child is not emotionally secured, he will experience hypervigilance and biological and psychological developments.

\section{Direction for future research}

One of the main objectives for impending research is to use ecological-transactional analysis to broaden the knowledge base on the significant interaction between biological processes like SNS, HPA axis, sleep, and psychological outcomes of children exposed to domestic violence. To achieve these goals, the following recommendations are suggested:

Effort should be guided toward understanding the socioecological interaction between child's biological disposition and the fusion of risk and protective factors and family milieu.

Future research should concentrate more on epigenetics as this helps in comprehending the extent of the relationship between biological and psychological processes, and other probable mechanisms that come from living in a risky family environment.

Researcher should understand and investigate the biological (stress response, emotion regulation, sleep) and the role they play in triggering and aggravating undesirable psychological functioning that explains individual and group differences. This, if managed, will help the practitioner and policy maker to identify risky families.

Likewise, professionals should identify strategies that will balance the child's needs with family's confidentiality.

Lastly, practitioners working with children exposed to domestic violence must learn and develop skills needed in providing crisis intervention, suitable assessment approaches and understanding child's development, and trauma.

With the information above, professionals and other stakeholders will be able to design strategies and ideas that not only meet the prevention and interference programme, but also change the trajectories of exposure to domestic violence.

\section{REFERENCES}

Barnish M (2004). Domestic violence: A literature review.HM Inspectorate of Probation.Downloaded from"http://www.homeoffice.gov.uk/justice/probation/inspprob/index.

Biersteker L, Robinson S (2000). Socio-economic policies: Their impact on children in South Africa. In D. Donald, A. Dawes \& J. Louw (Eds.), Addressing childhood adversity (pp. 26-59). Cape Town, SA: David Philip.

Boyce WT, Ellis BJ (2005). Biological sensitivity to context: I. An evolutionary-Developmental theory of the origins and functions of stress reactivity. Dev. Psychopathol., 17:271-301.

Bradley RH, Corwyn RF (2002). Socio economic status and child development. Ann. Rev. Psychol. 53: 371-399.

Bronfenbrenner U (1994). Ecological models of human development. Int. Encyclopedia Educ. 3: 2nd. Ed. Elsevier: Oxford.

Buckley H, Holt S, Whelan S (2007). Listen to me! Children's experiences of domestic violence. Child Abuse Rev. 16:296-310.

Carlson BE (2000) Children Exposed to Intimate Partner Violence.Trauma, Violence Abuse. 1(4): 321-342.

Center for Disease Control and Prevention (2013). The Adverse Childhood experiences (ACE) study. Retrieved from http://www.cdc.gov/ace/index.htm

Chapman DP, Liu Y, Presley-Cantrell LR, Edwards VJ, Wheaton AG Perry GS, Croft JB (2013). Adverse childhood experiences and frequent insufficient sleep in 5 U.S. States, 2009: A retrospective cohort study. BMC Public Health 13:3. 
Christian CW, Scribano P, Seidl T, Pinto-Martin J (1997). Pediatric injury resulting from family violence. Pediatrics 99.

Cicchetti D, Toth SL (2005). Child Maltreatment. Ann. Rev. Clin. Psychol. 1:409-438.

Cicchetti D (2002). How a child builds a brain: Insights from normality and psychopathology. In: Hartup, W.;Weinberg, R., editors. Minnesota symposia on child psychology: Child psychology in retrospect and prospect. Vol. 32. Mahwah, NJ: Lawrence Erlbaum Associates.

Cicchetti D, Rogosch FA (2001). The impact of child maltreatment and psychopathology Upon neuroendocrine functioning. Development and Psychopathology, 13,783-804.

Cicchetti D, Rogosch FA, Toth SL (1998). Maternal depressive disorder and contextual risk: Contributions to the development of attachment insecurity and behavior problems in toddlerhood. Dev. Psychopathol., 10:283-300.

Cicchetti D, Howes PW (1991). Developmental psychopathology in the context of the family: Illustrations from the study of child maltreatment. Can. J. Behav. Sci. 23(3): 257-281.

Cummings EM, Davies P (2010). Marital conflict and children: An emotional security perspective. New York: Guilford Press.

Cummings EM, El-Sheikh M, Kouros CD, Buckhalt JA (2009). Children and Violence: The Role of Children's Regulation in the Marital Aggression - Child Adjustment Link. Clinical Child Fam. Psychol. Rev. 12:3-15.

Cummings EM, Schermerhorn AC, Davies PT, Goeke-Morey MC, Cummings J (2006). Interparental discord and child adjustment: Prospective investigations of Emotional security as an explanatory mechanism. Child Dev. 77:132-152.

Cummings EM, Davies PD (1994). Children and marital conflict: The impact of family dispute and resolution, Guildford Press, New York.

Davies PT, Sturge-Apple ML (2007). Advances in the formulation of emotional security theory: An ethologically-based perspective. Advances in Child Behavior and Development, 35, 87-137.

Davies PT, Cummings EM (1994). Marital conflict and child adjustment: An emotional security hypothesis. Psychol. Bull., 116: 387-411.

Dawes A, Donald N (2000). Improving children"s chances: Linking developmental theory and practice. In D. Donald, A. Dawes \& J. Louw. (Eds.). Addressing childhood adversity (pp. 1-26). Cape Town \& Johannesburg: David Phillip.

Dembroski TM, MacDougall JM, Williams RB, Haney TL, Blumenthal JA (1985). Components of Type A, hostility, and anger-in: Relationship to angiographic findings. Psychosomatic Med. 47:219-233.

Dodd LW (2009). Therapeutic group work with young children and mothers who have experienced domestic abuse. Educ. Psychol. Pract. 25(1): 21-36

Donald D, Lazarus S, Lolwana P (2006). Educational psychology in social context. 2nd ed. Cape Town: Oxford South Africa.

Dunn J, Davies L (2001). Sibling relationships and interparental conflict. In: Grych, J.; Fincham, F., editors. Child Development and Interparental Conflict. New York: Cambridge University Press; P. 273-290.

Edge MD, Ramel W, Drabant EM, Kuo JR, Parker KJ, Gross JJ (2009). For better or worse? Stress inoculation effects for implicit but not explicit anxiety. Depression Anxiety, 26: 831-837.

Edleson JL, Mbilinyi LF, Beeman SK, agemeister AK (2003) 'How Children are involved in Adult Domestic Violence'. J. Interpersonal Violence 18(1): 18-32

El-Sheikh M, Kouros CD, Erath S, Cummings EM, Keller P, Staton L (2009). Marital conflict and children's externalizing behavior: Interactions between parasympathetic and sympathetic nervous system activity. Monographs of the Society Res. Child Dev. 74(1): 1101.

El-Sheikh M, Harger JA, Whitson SM (2001). Exposure to interparental conflict and children's adjustment and physical health: The moderating role of vagal tone. Child Dev., 72(6):1617-1636.

Fantuzzo J, Boruch R, Beriama A, Atkins M, Marcus S (1997). Domestic violence and children: Prevalence and risk in five major US cities. J. Am. Acad. Child Adolescent Psychiatry 36:116-122.

Felitti VJ, Anda RF, Nordenberg D, Williamson DF, Apitz AM, Edwards V, Koss MP, Marks JS (1998). Relationship of childhood abuse and household dysfunction to many of the leading causes of death in adults. Am. J. Prevent. Med. 14: 245-258.

Finkelhor D, Ormrod RK, Turner HA (2007). Polyvictimization and trauma in a national longitudinal cohort. Dev. Psychopathol. 19(1): 149-166.

Frasure-Smith N, Lesperance $F$, Talajic M (1995). The impact of negative emotions on prognosis following myocardial infarction: Is it more than depression? Health Psychol. 14:388-398.

Gabowitz D, Zucker M, Cook A (2008). Neuropsychological assessment in clinical evaluation of children and adolescents with complex trauma. J. Child and Adolescent Trauma 1: 163-178.

Gerhardt S (2004). Why Love Matters. London.Routledge,

Gewirtz AH, Edleson JL (2007). Young Children's Exposure to Intimate Partner Violence:

Gold PW, Chrousos GP (2002). Organization of the stress system and its dysregulation in melancholic and atypical depression: High vs low $\mathrm{CRH} / \mathrm{NE}$ states. Molecular Psychiatry 7: 254-275.

Gordis EB, Margolin G, John RS (2001). Parents' hostility in dyadic marital and triadic family settings and children's behavior problems. J. Consult. Clinical Psychol. 69: 727-734.

Graham-Bermann SA (2001). Designing intervention evaluations for children exposed to domestic violence: Applications of research and theory. In S. A. Graham- Bermann (Ed.), Domestic violence in the lives of children (pp. 237-267. Washington, D.C: American Psychological Association.

Grych JH, Harold GT, Miles CJ (2003). A prospective investigation of appraisals as mediators of the link between interparental conflict and child adjustment. Child Dev. 74: 1176-1193.

Grych JH, Jouriles EN, Swank PR, McDonald R, Norwood WD (2000). Patterns of adjustment among children of battered women. J. Consult. Clin. Psychol, 68: 84-94.

Gunnar M, Quevedo K (2007). The Neurobiology of Stress and Development. Annual Rev. Psychol. 58:145-173.

Gustafsson HC, Coffman JL, Harris LS, Langley HA, Ornstein PA, Cox MJ (2013), Intimate partner violence and children's memory. J. Fam. Psychol. 27(6): 937-944.

Hamber B, Lewis S (1997). An overview of the consequences of violence and trauma in South Africa. Johannesburg: Centre for the Study of Violence and Reconciliation.

Hanson MD, Chen E (2010). Daily stress, cortisol, and sleep: The moderating role of childhood psychosocial environments. Health Psychol. 29: 394-402.

Hetherington EM, Kelly J (2002). For better or for worse: Divorce reconsidered. New York: W.W. Norton.

Holt S, Buckley H, Whelan S (2008). The impact of exposure to domestic violence on children and young people: a review of the literature. Child Abuse Neglect .32: 797-810.

Holtzworth-Munroe A, Smutzler N, Sandin E (1997). A Brief Review of the Research on Husband Violence. Aggression Violent Behav. 2: 2.

Hughes HM, Luke DA (1998). Heterogeneity in adjustment among children of attered women. in G. W. Holden, R. Geffner, \& E. N Jouriles (Eds.), Children exposed to marital violence: Theory, research, and applied issues (pp. 185-221). Washington, DC: American Psychological Association.

Humphreys CSN (eds) (2006). Introduction. InDomestic Violence and Child Directions for Good Practice. London. Jessica Kingsley.

Jenkins EJ, Bell CC (1997). Exposure and response to community violence among children and adolescents. In J. Osofsky, (Ed.), Children in a Violent Society. New York, Guildford Press.

Jouriles EN, Brown AS, McDonald R, Rosenfield D, Leahy MM, Silver C (2008). Intimate partner Violence and preschoolers' explicit memory functioning. J. Fam. Psychol. 22(3):420-428.

Kershaw C, Nicholas S, Walker A (2008). Crime in England and Wales 2007/08. Home Office Statistical Bulletin. London: Home Office. [Online] Available at: 
http://homeoffice.gov.uk/rds/pdfs08/hosb0708.pdf.

Kitzmann KM, Gaylord NK, Holt AR, Kenny ED (2003). 'Child Witnesses to Domestic Violence: A Meta-Analytic Review'. J. Consult. Clin. Psychol. 71(2): 339-352.

Koss KJ, George MRW, Davies PT, Cicchetti D, Cummings EM, SturgeApple ML (2013). Patterns of children's adrenocortical reactivity to interparental conflict and associations with child adjustment: A growth mixture modeling approach. Dev. Psychol., 49(2): 317-326.

Kubzansky LD, Kawachi I, Weiss ST, Sparrow D (1998). Anxiety and coronary heart disease: A synthesis of epidemiological, psychological, and experimental evidence. Ann. Behav. Med. 20: 4758

Leec SL, Larkby CA, Day R, Day NL (2006). Predictors and correlates of high levels of depression and anxiety symptoms among children at age 10. J. Am. Acad. Child Adolescent Psychiatry 45:223-230.

Levendosky AA, Graham-Bermann SA (2000). Trauma and parenting in battered women: An addition to an ecological model of parenting. $\mathrm{J}$. Aggression Maltreatment Trauma 3: 25-35.

Lewis A (2009). Assessing childhood trauma: A holistic perspective. Child Abuse Res. S. Afr. 10(1): 14-26.

Luecken LJ, Lemery KS (2004). Early caregiving and physiological stress responses. Clinical Psychol. Rev. 24(2):171-191.

Margolin G (2005). Children's Exposure to Violence: Exploring Developmental Pathways to Diverse Outcomes. J. Interpersonal Violence 20: 72-81.

Margolin G, Gordis EB (2000). 'The effect of family and community violence on children'. Ann. Rev. Psychol. 51: 445-479.

Marshall J, Watt P (1999). Child Behaviour Problems: A Literature Review of the Size and Nature of the Problem and Prevention Interventions in Childhood, Perth, WA:

Masten AS, Reed MG (2002). Resilience in development. In S. R. Snyder \& S. J. Lopez (Eds.), The handbook of positive psychology. Oxford, England: Oxford University Press. The Interagency Committee on Children's Futures.

Masten AS, Hubbard JJ, Gest SD, Tellegen A, Garmezy N, Ramirez M (1999). Adaptation in the context of adversity: Pathways to resilience and maladaptation from childhood to late adolescence. Dev. Psychopathol. 11: 143-169.

Mathias J, Mertin P, Murray A (1995). 'The psychological functioning of children from backgrounds of domestic violence', Austr. Psychol. 30(1): 47-56.

McCloskey LA, Figueredo AJ, Koss MP (1995).The effects of systemic family violence on children's mental health. Child Dev. 66: 12391261.

McGee C (1997). Children's experiences of domestic violence. Child Fam. Social Work, 2: 13- 23.

Mclntosh J (2009). Legislating for shared parenting: Exploring some underlying assumptions. Fam. Court Rev. 47(3): 389-400.

Mclntosh JE (2002). Thought in the face of violence: a child's need. Child Abuse Neglect. (26): 229 - 241

Mullender A, Hague G, Iman U, Kelly L, Mallos E, Regan L (2002). Children's perspectives on domestic violence. London.Sage.

Osofsky JD (1997). Keeping your children safe: The violence intervention program for children and families. New Orleans, LA: LSU Medical Center, Dept of Psychiatry.

Osofosky J, Wewer S, Hann D, Fick A (1993). Chroniccommunity violence: What is happening to our children?Psychiatry: Interpersonal Biol. Process. 56: 36-45.

Osofsky JD (2003). Prevalence of children's exposure to domestic violence and child maltreatment: implications for prevention and intervention. Clin. Child Fam. Psychol. Rev. 6(3):161-170.

Peedicayil A, Sadowski LS, Jeyaseelan L, Shankar V, Jain D, Suresh S (2004). Spousal physical violence against women during pregnancy. BJOG, 111: 682-687

Plomin R, DeFries JC, Craig IW, McGuffin P (Eds.) (2003). Behavioral genetics. Washington DC: American Psychological Association.

Repetti R, Wang S, Saxbe D (2007). Bringing it all back home: How outside stressors shape families' everyday lives. Curr. Direct.
Psychol. Sci. 18:106-111.

Repetti RL, Taylor SE, Seeman TE (2002). Risky families: Family social environments and the mental and physical health of offspring. Psychol. Bull. 128: 330-366.

Richters JE, Martinez P (1993). The NIMH community violence project: I. Children as victims and witnesses toviolence. Psychiatry 56: 7-21.

Rivett M, Kelly S (2006). From awareness to practice: children, domestic violence and child welfare. Child Abuse Rev. 15.224-242 73

Russek LG, Schwartz GE (1997). Feelings of parental caring can predict health status in mid-life: A 35-year follow-up of the Harvard Mastery of Stress study. J. Behav. Med. 20(1): 13.

Rutter M, Sroufe LA (2000). Developmental psychopathology: Concepts and challenges. Dev. Psychopathol. 12: 265-296.

Rutter J (1997). Stand-up as Interaction: Performance and audience in comedy venues. Unpublished Ph.D. thesis, University of Salford, England.

Sbarra DA, Hasselmo K, Nojopranoto W (2012). Divorce and Death: A Case Study for Health Psychol. Soc. Personality Psychol. Compass 6(12): 905-919.

Sen S, Kranzler HR, Krystal JH, Speller H, Chan G, Gelernter J, Guille C (2010). A prospective cohort study investigating factors associated with depression during medical internship. Archives Gen. Psychiatry 67: $557-565$

Stavrou V (1993). Psychological effects of criminal and political violence on children. The Child Care Worker 11(7): 3-5.

Sternberg KJ, Baradaran LP, Abbott CB, Lamb ME, Guterman E (2006) Types of violence, age and gender differences in the effects of family violence on children's behaviour problems: a mega-analysis. Dev. Rev. 26: 89-112.

Sturge-Apple ML, Davies PT, Winter MA, Cummings EM ( 2008) Schermerhorn A. Interparental conflict and children's school adjustment: The explanatory role of children's internal representations of interparental and parent-child relationships. Dev. Psychol. 44:1678-1690.

Sturge-Apple ML, Davies PT, Cummings EM (2006). The impact of interparental hostility and withdrawal on parental emotional unavailability and children's adjustment difficulties. Child Dev. 77:1623-1641.

Sullivan M, Egan M, Gooch M (2004). Conjoint interventions for adult victims and children of domestic violence: a program evaluation. Res. Social Work Pract. 14:3

Sullivan CM, Juras J, Bybee D, Nguyen H, Allen N (2000). How children's adjustment is affected by their relationships to their mothers' abusers. J. Interpersonal Violence 15:587-602.

Susman EJ (2006). Psychobiology of persistent antisocial behavior: Stress, early vulnerabilities, and the attenuation hypothesis. Neurosci. Biobehav. Rev. 30: 376-389.

Swart E, Pettipher R (2005). A framework for understanding inclusion. In: $\mathrm{E}$ Landsberg, D Kruger and $\mathrm{N} \mathrm{Nel}$ (eds). Addressing Barriers to Learning. Pretoria: Van Schaik.

Taylor SE, Eisenberger NI, Saxbe D, Lehman BJ, Lieberman MD (2006). Neural responses to emotional stimuli are associated with childhood family stress. Biol. Psychiatry 60: 296-301.

Taylor SE, Lerner JS, Sage RM, Lehman BJ, Seeman TE (2004). Early environment, emotions, responses to stress, and health. J. Personal. 72:1365-1393

Walker EA, Gelfand A, Katon WJ, Koss MP, Von Korff M, Bernstein D (1999). Adult health status of women with histories of childhood abuse and neglect. The Am. J. Med. 107: 332-339.

Williams LM (2003). Understanding child abuse and violence against women: a life course perspective. J. Inter-personal Violence 18: 441

Wyman PA, Cowen EL, Work WC, Hoyt-Meyers L, Magnus KB, Fagen DB. (1999). Caregiving and developmental factors differentiating young at-risk urban children showing resilient versus stress-affected outcomes: A replication and extension. Child Dev. 70: 645-659. 

Int. J. Psychol. Couns.

Zeanah C, Danis B, Hirshberg L, Benoit D, Miller D, Heller S (1999). Disorganised attachment associated with partner violence: a research note', Infant Mental Health J. 20(1):77-86. 